\title{
Signaling intertrial shocks attenuates their negative effect on conditioned suppression
}

\author{
ROBERT A. RESCORLA \\ University of Pennsylvania, Philadelphia, Pennsylvania
}

\begin{abstract}
Three groups of rats were given Pavlovian fear conditioning in which footshocks occurred at a rate of .4 per $2 \mathrm{~min}$ in the presence of a light. For two of those groups, the light/shock contingency was degraded by the delivery of shocks at a rate of .2 per minute in the absence of the light. For one group, those additional shocks were signaled by a sequence of auditory stimuli; for the other group, they were unsignaled. A subsequent test of the light's ability to suppress ongoing leverpressing found that shocks delivered in the absence of the light interfered with conditioning of the light. But that interference was reduced markedly when those shocks were signaled. The results are consistent with a view in which Pavlovian contingencies are mediated by background conditioning adversely affecting learning about signals of the reinforcer.
\end{abstract}

Modern discussions of Pavlovian conditioning often emphasize the importance of the contingency between the conditioned stimulus (CS) and the unconditioned stimulus (US). One empirical result that has encouraged that view is that otherwise effective CS-US contiguities can be rendered relatively ineffective by the presentation of the US in the time interval between CSs (e.g., Gamzu \& Williams, 1973; Rescorla, 1968). Indeed, under some circumstances, no conditioning of the CS occurs when the rate of US presentation in the absence of the CS matches that in its presence.

The major theoretical interpretations of this result have attempted an explanation in terms of an augmented notion of CS-US contiguity. Of prime importance to those interpretations has been the well-supported proposition that USs occurring in the absence of the CS act to condition contextual cues. That context conditioning has been suggested as playing two quite different roles. On the one hand, several theories (e.g., Mackintosh, 1975; Pearce \& Hall, 1980; Rescorla \& Wagner, 1972) have viewed context conditioning as preventing the conditioning of the CS on the occasions that it is paired with the US. According to such views, a well-conditioned context can function like a discrete stimulus to block the conditioning of another CS in its presence (cf. Kamin, 1968, 1969). On the other hand, one might view contextual conditioning as interfering, not with the conditioning of the CS, but with the exhibition of that conditioning. For instance, Gibbon (1981) and Gibbon and Balsam (1981) have argued that conditioning of a CS may proceed similarly whether or not the context has been conditioned; however, the organism may dis-

This research was supported by NSF Grants BNS78-01752 and BNS83-08176. Thanks are due Ruth Colwill, Paula Durlach, and Jim Grau for helpful comments. Requests for reprints should be sent to Robert A. Rescorla, Department of Psychology, University of Pennsylvania, 3815 Walnut Street, Philadelphia, PA 19104. play its learning about the CS more readily in a poorly conditioned context.

Durlach (1983) noted two differential predictions from these theories. First, they anticipate different outcomes should a CS that is poorly conditioned by virtue of USs occurring in its absence be tested in a different context. If the deficit is in learning, then little responding should occur to the CS, whatever its test context; if the deficit is attributable to contextual conditioning attenuating performance, then substantial responding should occur if the CS is presented in a poorly conditioned context. Second, learning accounts describe the blocking of the CS-US association by the context in terms of the context and the CS competing for associative strength. Consequently, they envision CSs as capable of blocking conditioning of the background in the same way that the background is capable of blocking conditioning of the CS. As a result, they anticipate that the impact of USs that occur in the absence of the CS could be dramatically reduced if those USs were signaled by some other stimulus. Under those circumstances, there would be less background conditioning and thus less blocking of conditioning of the CS by the background. Accounts of contingency in terms of the effect of background conditioning on performance (e.g., Gibbon \& Balsam, 1981) do not anticipate that outcome. Nor is that outcome clearly expected on the basis of a primitive notion of CS-US contingency (e.g., Rescorla, 1968).

Durlach (1983) provided evidence on both of these predictions from an autoshaping paradigm. She found results largely consistent with the view that background conditioning interferes with learning about the CS. A CS that had been trained with USs in its absence showed little evidence of conditioning when it was tested in a different, low-valued context. Moreover, signaling the USs that occurred in its absence substantially undermined their adverse effects. 
The present experiment examined the second of these two predictions in a conditioned suppression setting. There are two reasons that it is of particular interest to use the conditioned suppression procedure to explore the effect of signaling the "intertrial USs." First, it was in this setting that the first observations were made about the detrimental effects of presenting USs during the interval between CSs. Conditioned suppression experiments still provide some of the most systematic data available on those effects. Second, earlier attempts to remove the adverse effects of intertrial USs by signaling their occurrence have yielded weak (Rescorla, 1972) or no (Jenkins \& Shattuck, 1981) effects.

The experiment reported here incorporated three features intended to maximize detection of an effect of signaling the USs. First, it presented USs at a lower rate in the absence of the CS than in its presence. Available data (e.g., Rescorla, 1968) suggest that this should result in an intermediate level of conditioning of the CS, possibly increasing our ability to detect variations in conditioning. Second, in this experiment, the stimulus that signaled the intertrial USs had had an extensive history of pairing with that US. Thus, it should have been capable of blocking the conditioning of the background by that US on its every first occurrence (cf. Durlach, 1983). Finally, the signal of the intertrial USs was quite long $(2 \mathrm{~min})$ and consisted of three sequentially presented stimuli. The intention here was twofold: to provide an especially salient stimulus and to minimize the ability of that stimulus to produce secondorder conditioning of the background. It is important to realize that a stimulus that signals the intertrial US becomes conditioned itself and hence may act to produce second-order conditioning of the background. To the extent that this happens, the signal may have less of a total impact on contextual conditioning. Other evidence (e.g., Marlin, 1982; Rescorla, 1984) suggests that well-conditioned CSs indeed can produce substantial background conditioning that can adversely affect the conditioning of other CSs. In an attempt to reduce such second-order conditioning, this experiment followed the procedure of Grau and Rescorla (in press) in using a sequential signal. The early components of such a signal may be expected to develop relatively less conditioning; hence, the background alone is followed by a relatively poorly conditioned stimulus, and yet that stimulus initiates a sequence that signals the ultimate US. Under those conditions, less second-order conditioning of the background may result.

The experiment contained three groups, each of which received footshocks during a light CS. One group received no intertrial shocks, one received unsignaled intertrial shocks, and one received intertrial shocks signaled by an auditory stimulus sequence. The questions of interest were whether intertrial shocks would disrupt conditioning of the light and whether signaling those shocks by auditory sequence would attenuate that disruption.

\section{METHOD}

\section{Subjects and Apparatus}

The subjects were 32 locally bred Holtzman-derived male rats about 150 days old at the start of the experiment. They were maintained in individual cages at $80 \%$ of their free-feeding weights.

The apparatus consisted of eight identical Skinner boxes measuring $22.9 \times 20.3 \times 20.3 \mathrm{~cm}$. Each chamber had a recessed food magazine in the center of the end wall and a bar to the left of the magazine. The floor of the chamber was composed of $.48-\mathrm{cm}$ stainless-steel rods, spaced $1.9 \mathrm{~cm}$ apart. The grid could be electrified through a relay-sequence scrambler from a highvoltage, high-resistance shock source. The two end walls of the chamber were aluminum; the side walls and top were clear Plexiglas. During some portions of the experiment, these Skinner boxes were replaced by eight conditioning chambers, similar to those boxes except that all walls were blank. Each chamber was enclosed in a sound- and light-resistant shell. Mounted on the wall of this shell were a $6-W$ houselight and a speaker. The speaker permitted the presentation of an $1800-\mathrm{Hz}$ tone, a $250-\mathrm{Hz}$ tone interrupted at a rate of $2 / \mathrm{sec}$, or a white noise. These stimuli measured about $76 \mathrm{~dB}$ re $20 \mathrm{microN} / \mathrm{m}$ against a background level of $62 \mathrm{~dB}$. Experimental events were controlled and recorded automatically by relays and microprocessors located in an adjoining room.

\section{Procedure}

Initially, all animals were trained to barpress for $45-\mathrm{mg}$ food pellets (P. J. Noyes Co.). During the first session, food was delivered on a variable-time 1-min schedule; in addition, each barpress produced a pellet. Upon the completion of 50 barpresses, the session was terminated. On the next 5 days, the sessions were $90 \mathrm{~min}$ long and involved reinforcement for barpressing on a variable-interval (VI) schedule. For the first $20 \mathrm{~min}$ of the initial VI session, the schedule was VI 1-min. Thereafter, it was VI 2-min.

On each of the next 20 days, the conditioning chambers replaced the Skinner boxes, and conditioning was carried out with the auditory stimuli. Each day, the animals received eight trials, each of which consisted of $40 \mathrm{sec}$ of the $250-\mathrm{Hz}$ tone, followed immediately by $40 \mathrm{sec}$ of the $1800-\mathrm{Hz}$ tone, followed immediately by $40 \mathrm{sec}$ of white noise. The white noise terminated in a $1-\mathrm{mA} .5-\mathrm{sec}$ footshock. The intention of this training was to give all groups equivalent conditioning of the auditory sequence that would subsequently be used to signal the intertrial shocks in one of the groups. Extensive training was used to encourage the development of a sequential discrimination reducing the conditioning of the initial auditory stimulus (cf. Newlin \& LoLordo, 1976; Williams, 1965).

On each of the next 12 days, the animals received conditioning of the light CS in the conditioning chambers. Each session contained $122-\mathrm{min}$ presentations of the houselight. For all animals, shocks occurred at a rate of .4 per 2 min when that light was on. Shocks were delivered randomly in time during that 2 min according to a different schedule each day. The animals in Group $N(n=8)$ received no additional stimuli. The animals in Group $U(n=8)$ received additional unsignaled shocks delivered randomly at a rate of .2 per $2 \mathrm{~min}$ in the absence of the light CS. The animals in Group $S(n=16)$ received those same intertrial shocks, but each was signaled by the three-component auditory sequence previously conditioned. All conditioning sessions were $90 \mathrm{~min}$ long.

On each of the next 3 days, the animals received reexposure to the VI schedule of food reinforcement in the Skinner boxes. This was done to ensure stable rates of responding in the absence of the CS in all groups.

On the next 2 days, the animals received test presentations of the CSs. Each day contained four 2-min presentations of a stimulus, delivered without consequence as the animal engaged in 
barpressing. On the 1st of these days, the light CS was tested. The differential suppressions during this stimulus are the data of primary interest. On the next day, the auditory stimulus used to signal the intertrial USs was tested, to determine whether the initial stimulus in the sequence did, in fact, produce less suppression.

The measure of conditioning of the CSs was the degree to which their presentation interrupted ongoing barpressing. For this purpose, a suppression ratio of the form $A /(A+B)$ was computed, where $A$ is the response rate during the CS and $B$ is the rate in a comparable period prior to CS onset. Substantial conditioning, and hence interruption of performance, results in a suppression ratio near zero, whereas little conditioning produces a ratio near .5 .

\section{RESULTS}

Performance on the VI schedule of reinforcement developed without incident. By the final day, the mean rate of responding was 10.2 per minute and was not different among groups. However, during the first recovery session, after the intervening conditioning, group differences in barpressing did emerge. On that day, the mean barpress rates for Groups $\mathrm{N}, \mathrm{S}$, and $\mathrm{U}$ were 12.2, 13.8 , and 6.0, respectively. Although the groups receiving no intertrial shocks or signaled intertrial shocks did not differ, both Group S and Group N responded more rapidly than did the animals receiving unsignaled shocks (Mann-Whitney Us $=25$ and 12, respectively, ps $<.01$ ). However, by the final day of recovery, the groups performed at similar rates. On that day, the mean rates were $8.5,9.9$, and 8.7 responses per minute for Groups $\mathrm{N}$, $\mathrm{S}$, and $\mathrm{U}$, respectively.

The data of primary interest, from the test session with the light CS, are shown in Figure 1. That figure

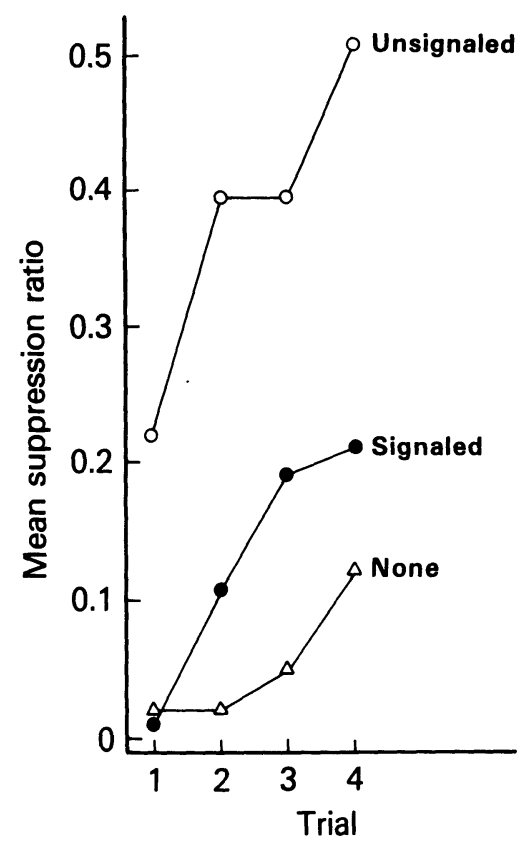

Figure 1. Mean suppression ratio for each trial of the test session. The groups differed in having received signaled, unsignaled, or no intertrial shocks during conditioning. displays the trial-by-trial suppression ratios over the course of the extinction test session. Initially, there was some suppression in all three groups. However, throughout extinction testing, Group U showed substantially less suppression than either Group S or Group N. That difference was reliable on the initial test trial (Us $=14.5$ and 7.5, ps $<.02$ ) as well as over the total session (Us = 13 and 5 , ps < .02). In addition, Group S showed a tendency to extinguish more rapidly than did Group N; however, that difference was reliable only on Trial 3 $(\mathrm{U}=30, \mathrm{p}<.05)$. The pre-CS rates ranged from 8.4 to 10.2 , with no reliable differences among the groups.

The pattern of suppression to the auditory stimuli on the next day was one of decreased responding as the time of the US approached. The mean suppression ratios were $.21, .20$, and .08 for the three successive stimuli in Group S, which had received the most extensive experience with these stimuli. The comparable ratios were $.15, .09$, and .04 for Groups $U$ and $N$ combined. Although none of the groups differed reliably from the other two, overall there was greater conditioning to the final stimulus in the sequence than to the first stimulus [Wilcoxon $\mathrm{T}(25)=18, \mathrm{p}<.05$ ]

\section{DISCUSSION}

This experiment provided support for a learning interpretation of the adverse effects of intertrial USs on the conditioning of a CS. First, signaling of those intertrial USs had two effects anticipated by learning accounts. (1) It apparently attenuated the general level of context conditioning produced by those USs; although Group U showed considerable overall suppression of behavior on the first recovery session following conditioning, Group S was not different from a group lacking intertiral USs. (2) More importantly, it removed much of the consequence of intertrial USs for the conditioning of the original CS. Both those observations suggest the sort of competition between background and CS conditioning envisioned by learning accounts. Second, in the present studies, the eventual test was administered in a context in which the animal had received substantial nonshock experience. If one can take similar baseline rates of responding to indicate similar levels of context conditioning in the various groups, then context conditioning does not provide an account of the different levels of suppression to the CS. Rather, those differences must reside in enduring properties of the $\mathrm{CS}$ as a result of its prior conditioning treatment.

These results also comment on an issue recently raised by Jenkins and Shattuck (1981). They noted that the addition of USs in the time between CSs not only reduces the CS/US contingency, but also increases the overall density of USs. They suggested that it may be this later feature that reduces responding to the CS. Jenkins and Shattuck evaluated this possibility by comparing the effects of adding intertrial USs that either were unsignaled or were signaled by the original CS. They found these two procedures, both of which increase overall US density but which differ in the degree to which that addition attenuates the CS/US contingency, to produce comparable adverse effects on performance. They suggested that the results are better understood in terms of the relative waiting time hypothesis (Jenkins, Barnes, \& Barrera, 1981), in which conditioning depends on the rate of the US during the CS compared with that in the session as a whole.

The present experiment provided some evidence on both the empirical issue that Jenkins et al. (1981) raised and on the theoretical alternative that they offered. Groups $S$ and $U$ shared the same US pattern both in the presence and in the absence of the 
original CS; they differed only in that for Group S the USs delivered in the absence of that CS were signaled by another stimulus. Yet Group $U$ showed relatively little conditioning, whereas Group S showed almost as much evidence of conditioning as did a group lacking the intertrial USs. That suggests that it is not the overall shock density per se that attenuates performance, but, rather, some feature of the manner in which those shocks are delivered. Contingency notions are sufficiently vague as to be unclear whether or not signaling of the intertrial shocks should be taken as affecting the degree that they disrupt the CS/US contingency. But the results of the signaling observed in the present experiment are more consistent with attempts to explicate contingency in terms of the background blocking learning about the CS than in terms of the relative waiting time hypothesis.

Why the results of the present experiment differed from those of the Jenkins and Shattuck (1981) experiment is not clear. The procedures of the experiments differed in a number of potentially relevant ways. However, the decision by Jenkins and Shattuck to use the CS itself to signal intertrial USs introduced other important changes. For instance, a group with intertrial USs signaled in this way must receive a substantially greater number of CS presentations than either a group lacking intertrial USs or one receiving them in an unsignaled fashion. The present procedure of using another stimulus to accomplish that signaling allows one to better match the treatment of the original CS across groups that differ only in their intertrial experience.

In the present experiment, particular measures were taken to ensure that the intertrial USs were well signaled by a stimulus that might not produce much second-order conditioning of the context. To what extent these measures were critical to the present results is not clear. However, it is clear that substantial pretraining of the auditory stimulus sequence arranged for it to be an excellent signal of the US under conditions of only moderate conditioning of the initial stimulus in the sequence. Under those conditions, that sequence markedly attenuated the adverse effects of the intertrial USs it signaled.

\section{REFERENCES}

Durlach, P. J. (1983). Effect of signaling intertrial unconditioned stimuli in autoshaping. Journal of Experimental Psychology: Animal Behavior Processes, 9, 374-389.

Gamzu, E., \& Williams, D. R. (1973). Associative factors underlying the pigeon's keypecking in autoshaping procedures. Journal of the Experimental Analysis of Behavior, 19, 225-232.

GibBoN, J. (1981). The contingency problem in autoshaping. In C. M. Locurto, H. S. Terrace, \& J. Gibbon (Eds.), Autoshaping and conditioning theory. New York: Academic Press.

GibBon, J., \& Balsam, P. (1981). Spreading association in time. In C. M. Locurto, H. S. Terrace, \& J. Gibbon (Eds.), Autoshaping and conditioning theory. New York: Academic Press.
Grau, J. W., \& Rescorla, R. A. (in press). The role of context in autoshaping. Journal of Experimental Psychology: Animal Behavior Processes.

Jenkins, H. M., Barnes, R. A., \& Barrera, F. J. (1981). Why autoshaping depends on trial spacing. In C. M. Locurto, H. S. Terrace, \& J. Gibbon (Eds.), Autoshaping and conditioning theory. New York: Academic Press.

Jenkins, H. M., \& Shattuck, D. (1981). Contingency in fear conditioning: A reexamination. Bulletin of the Psychonomic Society, 17, 159-162.

KamiN, L. J. (1968). "Attention-like" processes in classical conditioning. In M. R. Jones (Ed.), Miami Symposium on the Prediction of Behavior, Coral Gables, FL: University of Miami Press.

Kamin, L. J. (1969). Predictability, surprise, attention, and conditioning. In B. A. Campbell \& R. M. Church (Eds.), Punishment and aversive behavior. New York: Appleton-CenturyCrofts.

Mackintosh, H. J. (1975). A theory of attention: Variations in the associability of stimuli with reinforcement. Psychological Review, 82, 276-298.

Marlin, N. A. (1982). Within-compound associations between the context and the conditioned stimulus. Learning and Motivation, 13, 526-541.

Newlin, R. J., LoLordo, V. M. (1976). A comparison of pecking generated by serial, delay, and trace autoshaping procedures. Journal of the Experimental Analysis of Behavior, 25, 227-241.

Pearce, J. M., \& Hall, J. (1980). A model for Pavlovian learning: Variations in the effectiveness of conditioned but not of unconditioned stimuli. Psychological Review, 87, 532-552.

Rescorla, R. A. (1968). Probability of shock in the presence and absence of CS in fear conditioning. Journal of Comparative and Physiological Psychology, 66, 1-5.

Rescorla, R. A. (1972). Informational variables in Pavlovian conditioning. In G. H. Bower (Ed.), The psychology of learning and motivation (Vol. 6). New York: Academic Press.

Rescorla, R. A. (1984). Associations between Pavlovian CSs and context. Journal of Experimental Psychology: Animal Behavior Processes, 10, 195-204.

Rescorla, R. A., \& Wagner, A. R. (1972). A theory of Pavlovian conditioning: Variations in the effectiveness of reinforcement and nonreinforcement. In A. H. Black \& W. F. Prokasy (Eds.), Classical conditioning II. New York: Appleton-CenturyCrofts.

Williams, D. R. (1965). Classical conditioning and incentive motivation. In W. F. Prokasy (Ed.), Classical conditioning. New York: Appleton-Century-Crofts.

(Manuscript received for publication January 29, 1984.) 